Eake Engineering

\title{
Post-earthquake Performance of a Slab-Column Connection with Punching Shear Reinforcement
}

\section{Brisid Isufi, António Pinho Ramos \& Válter Lúcio}

To cite this article: Brisid Isufi, António Pinho Ramos \& Válter Lúcio (2020): Post-earthquake Performance of a Slab-Column Connection with Punching Shear Reinforcement, Journal of Earthquake Engineering, DOI: 10.1080/13632469.2020.1713924

To link to this article: https://doi.org/10.1080/13632469.2020.1713924

\section{曲 Published online: 21 Jan 2020.}

Submit your article to this journal $₫$

山ll Article views: 175

Q View related articles $₫$

View Crossmark data \lceil

4

Citing articles: 1 View citing articles $₫$ 


\title{
Post-earthquake Performance of a Slab-Column Connection with Punching Shear Reinforcement
}

\author{
Brisid Isufi (1) ${ }^{\mathrm{a}}$, António Pinho Ramos (10) ${ }^{\mathrm{a}, \mathrm{b}}$, and Válter Lúcio (1D)

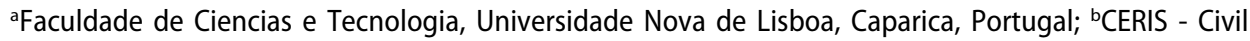 \\ Engineering Research and Innovation for Sustainability, University of Lisbon, Lisbon, Portugal
}

\begin{abstract}
Brittle punching failures can occur in slab-column connections due to earthquake-induced unbalanced moments. The performance of undamaged specimens and various repair/strengthening techniques have been studied in the past. This paper investigates a less studied scenario, in which a flat slab-column connection severely damaged by an earthquake is subjected to another earthquake without undergoing repair. The performance under this special loading protocol is analysed. It is shown that the drift capacity was not significantly impaired, but both the lateral and bending stiffness were reduced. Other relevant observations regarding the post-earthquake life of slab-column connections are brought to attention.
\end{abstract}

\section{ARTICLE HISTORY}

Received 16 November 2018

Accepted 2 January 2020

\section{KEYWORDS}

Cyclic Loading; Drift; Flat Slab; Post-Earthquake; Studs; Punching

\section{Introduction}

Major seismic events can cause collapse or unrepairable damage that requires demolition of the structure. Besides unrepairable damage, the decision to demolish structures after an earthquake is often guided by the uncertainty regarding the expected seismic performance during the post-earthquake life (Marder et al. 2018). The controlled demolitions after the 2010-2011 Canterbury earthquakes represent an example in which the perceived risk due to uncertainties played a role among other factors (Marquis et al. 2017). Understanding the remaining capacity of structures after an earthquake is therefore of interest in terms of safety and economy. In structures containing flat slabs, the issue is especially relevant, because of the risk of punching shear failures that can cause a progressive collapse of the entire structure.

Due to the complexity of the behaviour and limitations of experimental works, the seismic behaviour of slab-column connections remains an active topic of research and still not entirely covered by the design codes (for example, the current version of Eurocode 8 (CEN 2004b)). When used in buildings in highly seismic regions, structures with flat slabs normally have shear walls, moment-resisting frames or braces and the contribution of flat slabs towards the resistance for horizontal actions is usually neglected. Nonetheless, flat slabs must possess sufficient deformation capacity to prevent brittle punching failures while undergoing deformations imposed by the primary seismic load resisting system.

A thorough literature review revealed that tests reported on slab-column connections to study their seismic behaviour mainly fall into one of the categories summarized in

CONTACT Brisid Isufi b.isufi@campus.fct.unl.pt $\Theta$ Faculdade de Ciencias e Tecnologia, Universidade Nova de Lisboa, Caparica 2829-516, Portugal

(C) 2020 Taylor \& Francis Group, LLC 
a)

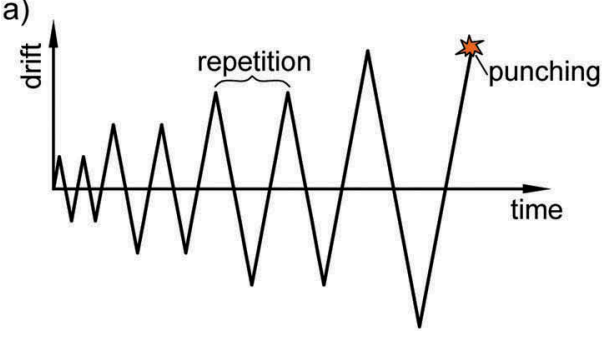

b)

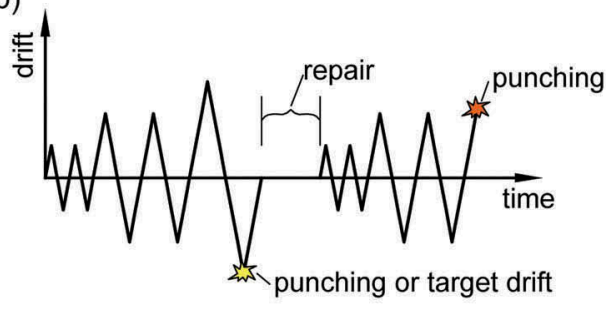

Figure 1. Loading protocols used in past experimental works to study the seismic behaviour of flat slab-column connections.

Fig. 1. The most common type of test is the one described in Fig. 1a, where reversed horizontal loading is applied up to failure, with repetition of drifts to study stiffness degradation before going to the next drift level. These tests aim to address mainly the issue of drift capacity under lateral loading. Research has shown that one of the most practical methods of enhancing drift capacity is the use of shear reinforcement in the slab region around the column. Horizontal cyclic loading tests of flat slab-column connections (refer, for example, to (Hueste et al. 2007) for a summary) have demonstrated that the ultimate drift of connections with punching shear reinforcement (stirrups, headed studs, and other types of shear reinforcement) is significantly higher than the drift capacity of similar specimens without shear reinforcement.

Another important category of experiments found in the literature consists in reversed horizontal cyclic loading tests of repaired slab-column connections, as illustrated in Fig. 1b. Tests reported in Pan and Moehle (1992), Farhey, Adin, and Yankelevsky (1995), Widianto et al. (2010) and Robertson and Johnson (2004) fall into this category. These tests provide valuable information on the post-earthquake performance of slab-column connections that undergo repair or strengthening works after a major seismic event. Cases of repair after punching failure (Farhey, Adin, and Yankelevsky 1995; Pan and Moehle 1992) as well as repair (or strengthening) after a target drift (Robertson and Johnson 2004; Widianto et al. 2010) have been reported. Repair and strengthening techniques tested in the aforementioned publications with varying degree of success include epoxy grout repair, installation of external steel plates, carbon fibre-reinforced polymer (CFRP) stirrups and CFRP sheets on the top surface of the slab.

Other studies that have provided relevant information on the safety of flat slab-column connections are those focused on the post-punching behaviour of flat slabs (Faria, Lúcio, and Ramos 2012; Habibi, Cook, and Mitchell 2014; Melo and Regan 1998; Mitchell and Cook 1984; Ramos and Lúcio 2008; Ruiz, Mirzaei, and Muttoni 2013). These studies have led to a better understanding of the necessary measures that need to be taken to prevent the progressive collapse of flat-slab buildings when a punching failure occurs under seismic loading conditions (for example, the provision of integrity reinforcement). Experiments that aim to determine the residual punching shear strength after the application of horizontal cyclic loading include Megally and Ghali (2000) and Widianto et al. (2010). The effects of the loading history were investigated for gravity loading in Koppitz, Kenel, and Keller 
(2015), which showed that unloading and reloading the flat slab has little effect on the punching shear resistance for most common cases.

However, no study from the literature focused on the post-earthquake seismic performance of unrepaired flat slabs was found. Based on the available experimental evidence to date, however, it is not clear whether flat slabs that survive large imposed drifts (i.e., without failing in punching) after a seismic event are adequate for the postearthquake life of the structure without undergoing major repair works.

In this context, the detailed analysis of the post-earthquake behaviour of a flat-slab specimen with headed stud shear reinforcement is presented in this paper. The specimen is named C-SSR5b and it is part of the experimental campaign described in Isufi, Pinho Ramos, and Lúcio (2019). The experimental program included reversed horizontal loading tests of five flat slab-column subassemblies, four of which were reinforced with studs distributed in cruciform layouts around the column. The specimen C-SSR5b is reexamined in depth in this paper in a first attempt to provide insight on the postearthquake performance of unrepaired slab-column connections.

\section{Reversed Horizontal Cyclic Loading Test}

\subsection{Specimen's Geometry and Test Setup}

The overall dimensions of the tested slab were $4.15 \mathrm{~m}$ by $1.85 \mathrm{~m}$ with a thickness of $0.15 \mathrm{~m}$. A steel column with a length of $2.00 \mathrm{~m}$ (total length below and above the slab) and a rigid square base plate with side dimension equal to $250 \mathrm{~mm}$ were used (Fig. 2). The subassembly represents a $2 / 3$ scale model of the column from mid-storey to mid-storey and the slab portion from mid-span to mid-span in the longitudinal direction (horizontal loading direction) and $44 \%$ of the span length in the transversal direction (22\% on each side, roughly corresponding to the zero-moment line) in the prototype building (Fig. 2). The slab was reinforced with $12 \mathrm{~mm}$ top bars in the column region and $10 \mathrm{~mm}$ bars elsewhere (Fig. 2), resulting in a top-longitudinal reinforcement ratio of $0.97 \%$. Detailing of the top and bottom bars was nominally identical to that of the specimens described in Almeida et al. (2016)

Shear reinforcement consisted of $8 \mathrm{~mm}$ reinforcing steel bars welded into rectangular $25 \times 8 \mathrm{~mm}$ steel plates on top and square plates at the bottom. The layout of the shear reinforcement is shown in Fig. 3 and a photo of a shear stud assembly is provided in Fig. 4. A total of 60 studs were positioned in a cruciform layout with a uniform spacing of $70 \mathrm{~mm}$ in the radial direction. The distance of the first stud from the face of the column was $40 \mathrm{~mm}$ (Fig. 3). The reader is referred to Isufi, Pinho Ramos, and Lúcio (2019) for more details.

The main characteristics of the specimen are summarized in Table 1. In this table, $d$ is the average effective depth measured before casting. The concrete strength $f_{c}$ and the modulus of elasticity $E_{\mathrm{c}}$ are determined from the test of five cylinder specimens with a diameter of $150 \mathrm{~mm}$ and a height of $300 \mathrm{~mm}$, tested on the slab specimen test day. Tensile strength tests were performed on reinforcing bars to determine the yield stress of the top-longitudinal bars, $f_{\mathrm{y}}$, the yield stress of shear reinforcement legs (studs) $f_{\mathrm{yw}}$ and the yield strains $\varepsilon_{\mathrm{y}}$ and $\varepsilon_{\mathrm{yw}}$ corresponding to the top-longitudinal bars and the studs, respectively. Table 1 also contains the punching shear resistance $V_{0}$ calculated in accordance with Eurocode 2 (CEN 2004a) for concentric loading without the contribution of the shear 


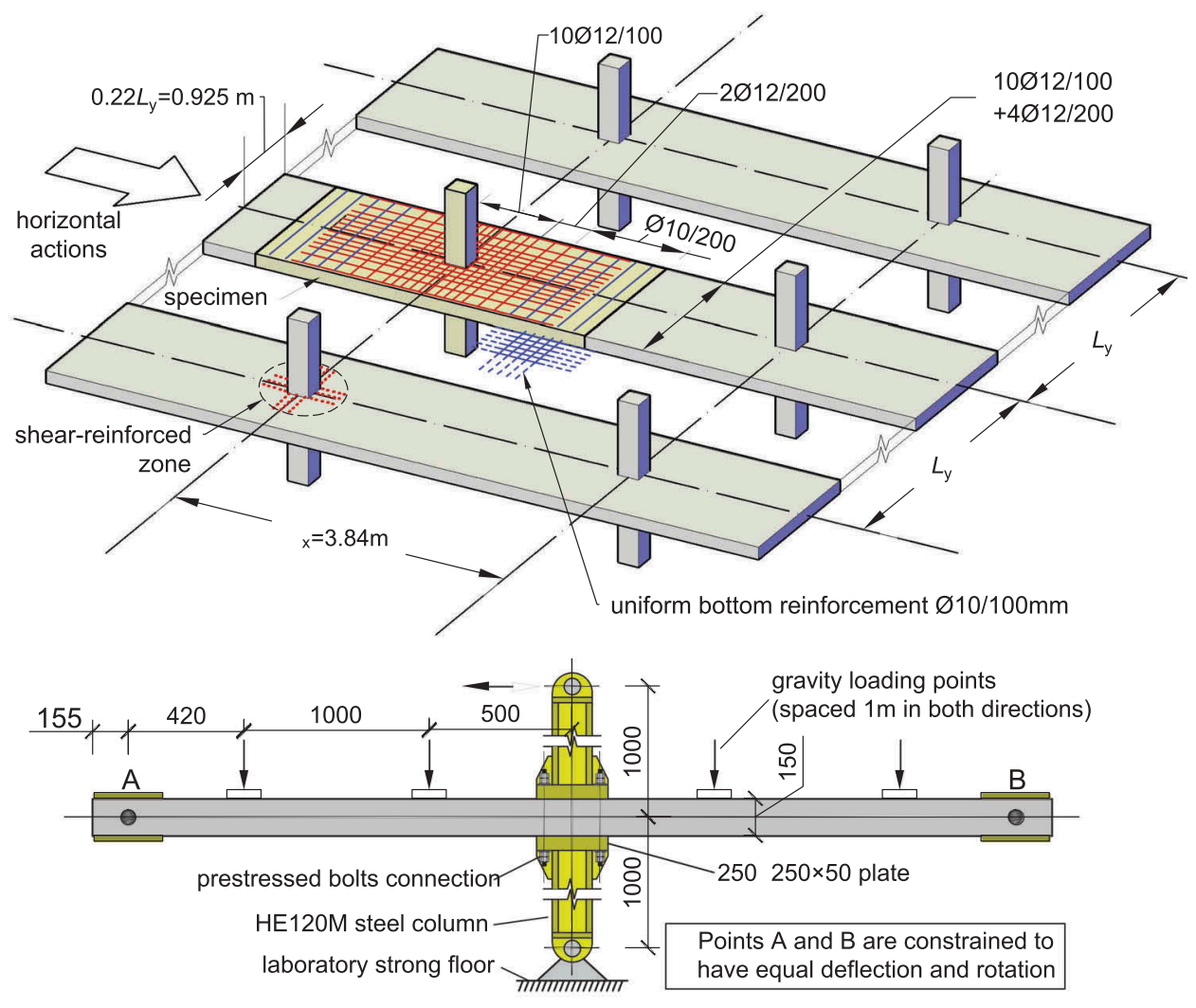

Figure 2. Specimen geometry and longitudinal reinforcement.

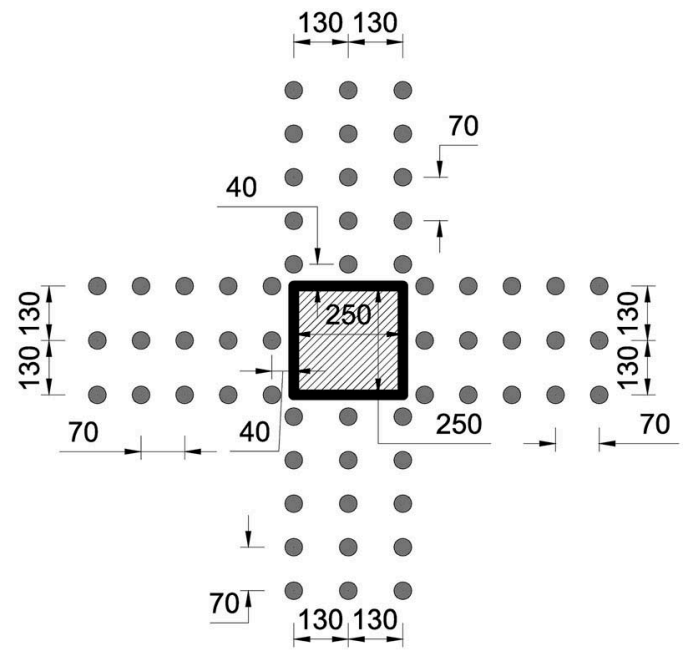

Figure 3. Layout of the shear reinforcement. 


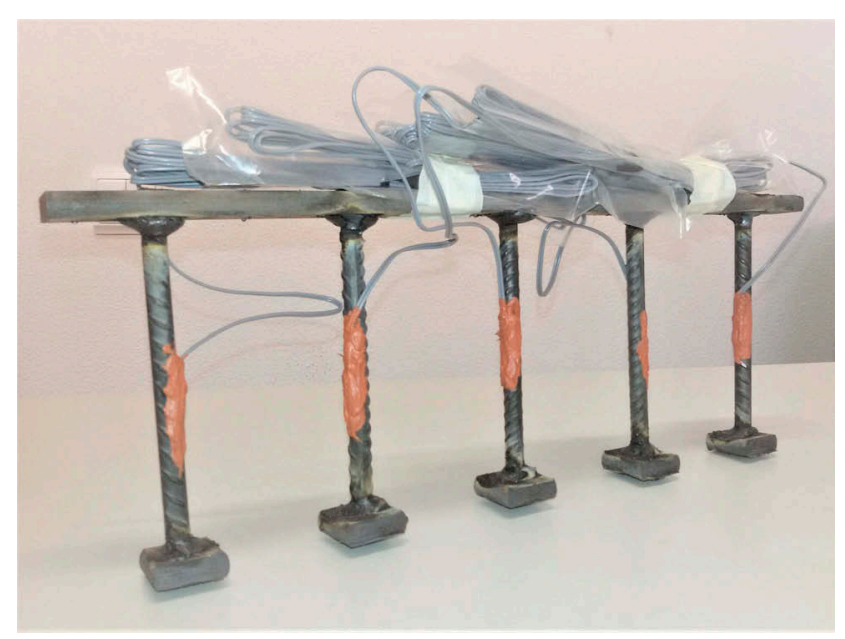

Figure 4. Photo of a stud assembly with strain gauges installed.

Table 1. Main characteristics of the specimen.

\begin{tabular}{lcccccccccc}
\hline Specimen & $d(\mathrm{~mm})$ & $f_{\mathrm{c}}(\mathrm{MPa})$ & $E_{\mathrm{c}}(\mathrm{GPa})$ & $f_{\mathrm{y}}(\mathrm{MPa})$ & $\varepsilon_{\mathrm{y}}(\%)$ & $f_{\mathrm{yw}}(\mathrm{MPa})$ & $\varepsilon_{\mathrm{yw}}(\%)$ & $V_{0}(\mathrm{kN})$ & $V_{\mathrm{g}}(\mathrm{kN})$ & $\mathrm{GSR}(\%)$ \\
\hline C-SSR5b & 117.1 & 57.6 & 38.8 & 541.9 & 0.27 & 488.8 & 0.24 & 397.9 & 213.9 & 53.8 \\
\hline
\end{tabular}

reinforcement, considering average values for the material properties. The shear force applied throughout the test is $V_{\mathrm{g}}$, equal to the slab's reaction on the column support and equal to the sum of all applied gravity loads plus self-weight of the specimen and equipment. The ratio $V_{\mathrm{g}} / V_{0}$ is commonly referred to as Gravity Shear Ratio (GSR). The load $V_{\mathrm{g}}$ represents the sum of vertical loads present in the structure under the seismic combination of actions.

The test setup of Fig. 5, described in detail in Almeida et al. (2016), was used. This setup allows for vertical displacements at the opposite slab borders (mid-span lines); equal magnitude shear forces, bending moments and rotations at the slab borders as well as mobility of the line of inflection location along the longitudinal direction during the

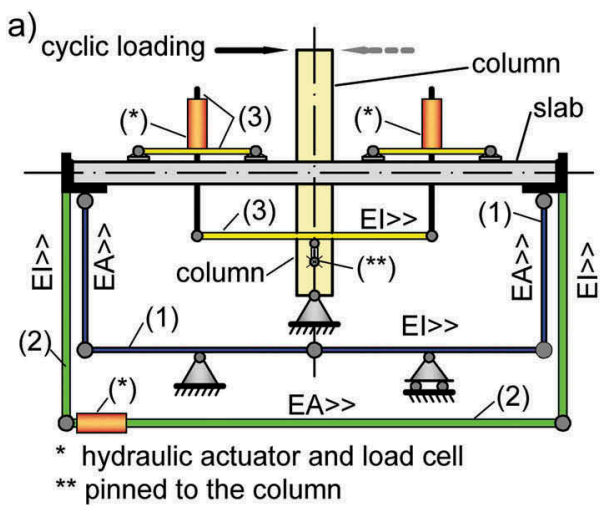

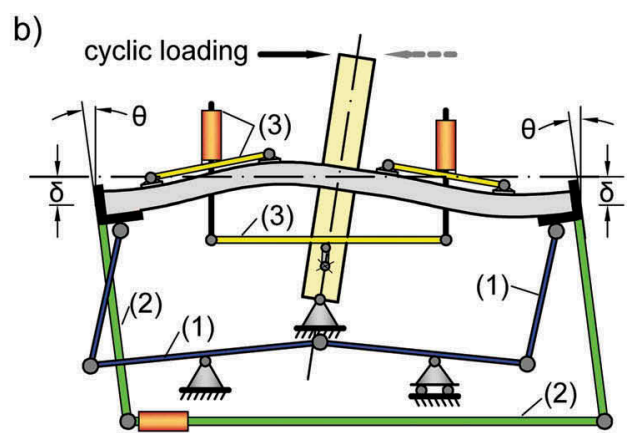

Not to scale

Figure 5. Test setup: (a) undeformed shape; (b) under combined gravity and lateral loading. 
application of horizontal drifts (refer to the elevation view in Fig. 2). These features are achieved by attaching two subassemblies to the borders of the specimen, denoted by (1) and (2) in Fig. 5a. The subassembly denoted by (3) is used to apply and maintain the gravity load (Isufi, Pinho Ramos, and Lúcio 2019). The gravity load is applied in eight points on the slab top surface, through the use of spreader beams and prestress tendons, and was kept constant during the application of the horizontal reversed cycles, as confirmed by the readings of the load cells installed in each hydraulic actuator. Constant gravity load for high drift ratios is ensured in this test setup due to the ability of subassembly (3) to follow the movements of the specimen without interference, as illustrated in Fig. 5b. The steel column was designed to remain elastic through the entire test. To ensure a proper connection of the steel column with the concrete slab, a conservatively designed prestressed bolts connection was used. The holes opened for the bolts were filled with grout. Additionally, the steel-column interface was evened out and epoxy resin was applied to fill any remaining surface imperfections.

A two-phase cyclic loading history was followed (Fig. 6), resulting in the following overall loading phases:

Phase I: application of the full gravity load; reversed horizontal cyclic loading until a horizontal drift ratio of $3.0 \%$ (only half a cycle, for positive drifts only) and unloading of the gravity and horizontal loads;

Phase II: re-application of the gravity load with the same GSR and restart of the horizontal loading protocol from zero drifts up to failure of the specimen.

This loading history for specimen C-SSR5b simulates a scenario in which the building experiences a major earthquake event (such that 3\% drifts are imposed on the slab-column connection) but the connections successfully carry the gravity loads without a punching

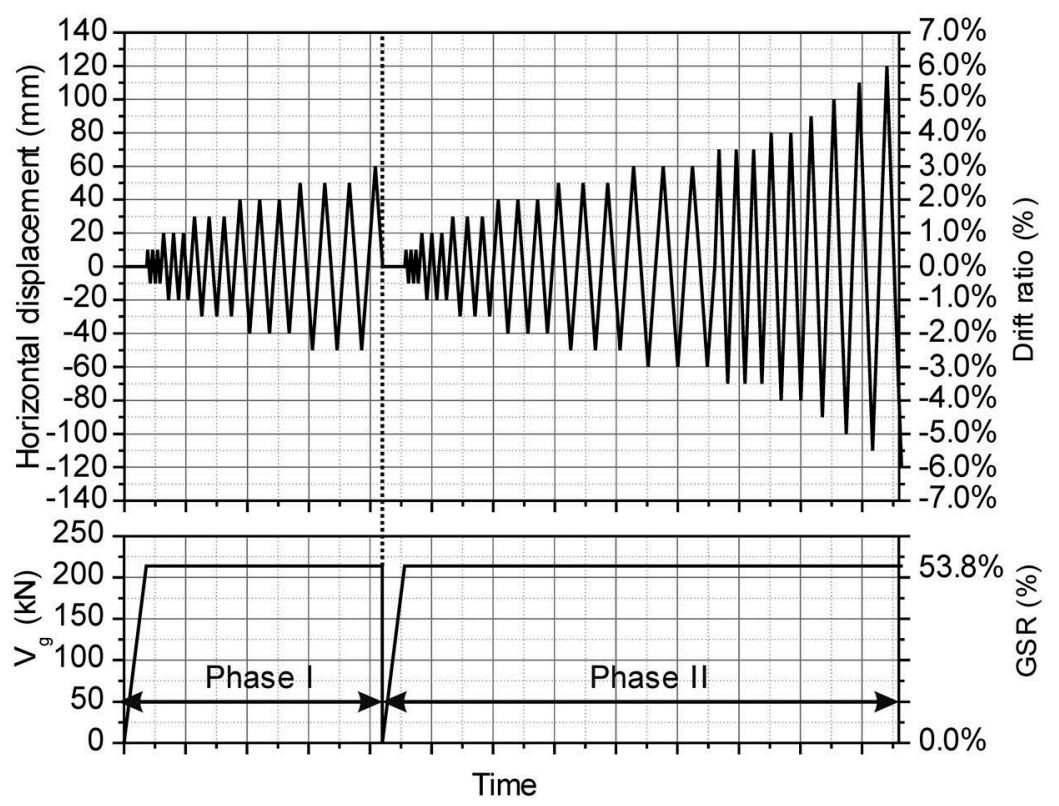

Figure 6. Loading protocol. 
failure. Reloading of the specimen is done to observe the strength and stiffness of the pretested specimen and to observe the behaviour for larger drifts. Target drifts are increased in steps of $0.5 \%$ until failure of the specimen with repetition of drift cycles as depicted in Fig. 6 . Cyclic horizontal drifts were applied at an average rate of $9 \mathrm{~mm} / \mathrm{min}$ for drifts up to $3.0 \%$ and $18 \mathrm{~mm} / \mathrm{min}$ for higher drifts.

\subsection{Main Observations}

\subsubsection{Phase I}

The slab specimen started to crack during the gravity loading phase. Small cracks were observed near the column. New cracks developed with the application of the first horizontal drifts, whereas the existing cracks opened further. At $1.0 \%$ drift, small radial cracks started to become visible. Cracking continued to extend with the increase of horizontal drifts. At $1.5 \%$ drift, the crack next to the face of the column opened considerably (Fig. 7a). The entire slab was cracked (i.e., including positive bending moment regions). There was a steady growth of the cracks until $3.0 \%$ drift (Fig. $7 b, c$ ). After the completion of the first $3.0 \%$ drift, the slab was severely cracked along the entire span. Limited damage consisting in concrete crushing could be observed in the perimeter of the column on the bottom face of the slab (Fig. 7d) but no signs of an imminent punching failure were detected.

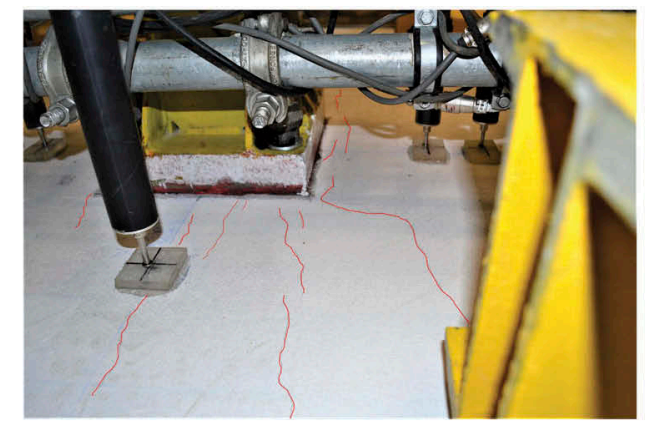

(a)

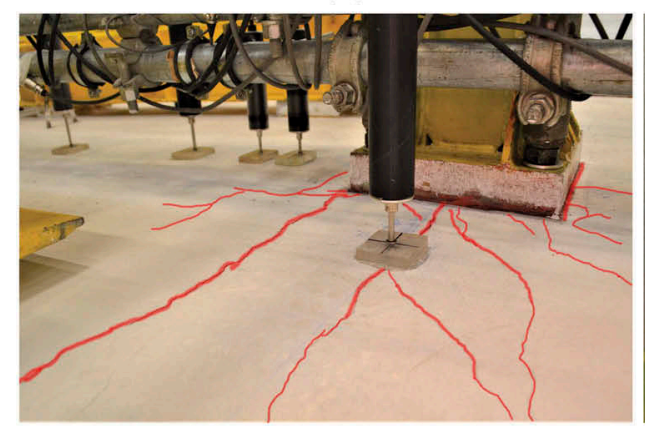

(c)

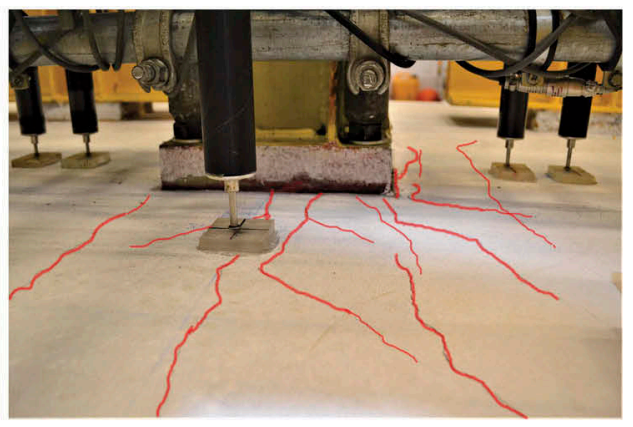

(b)

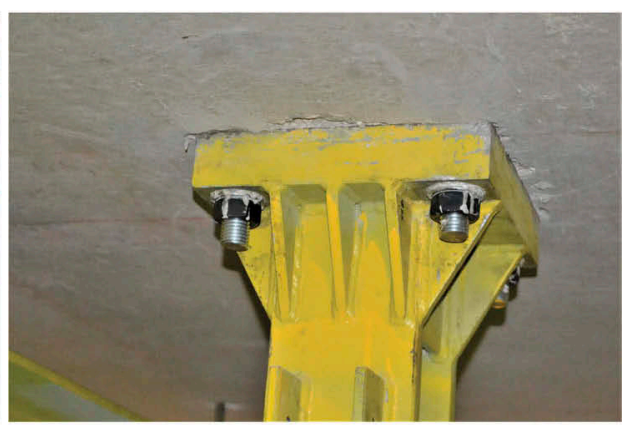

(d)

Figure 7. Pictures during the first phase of cyclic loading test: (a) $1.5 \% \mathrm{drift}$; (b) $2.5 \% \mathrm{drift}$; (c) $3.0 \% \mathrm{drift}$ (top surface); (d) $3.0 \%$ drift (bottom surface). 


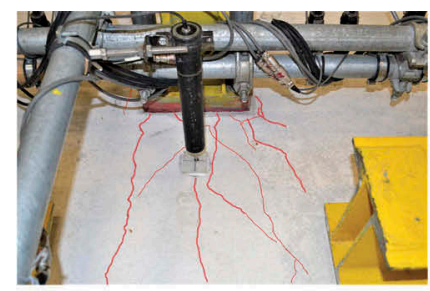

(a)

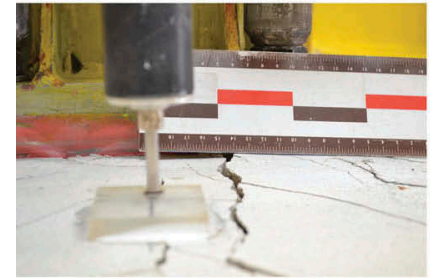

(d)

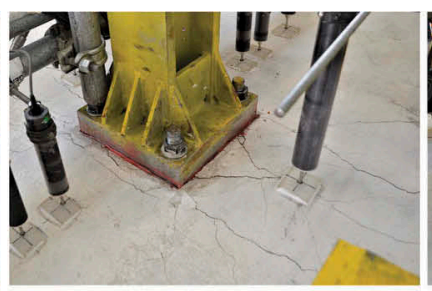

(b)

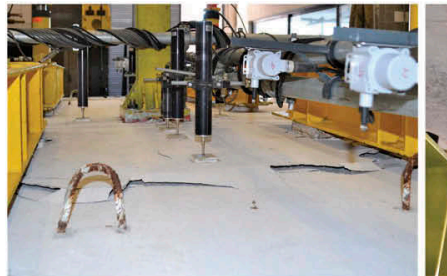

(e)

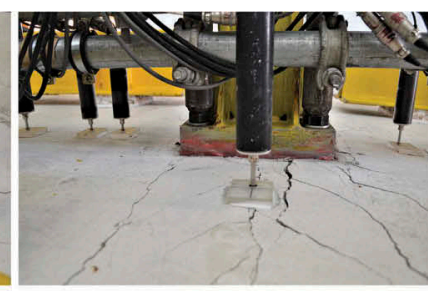

(c)

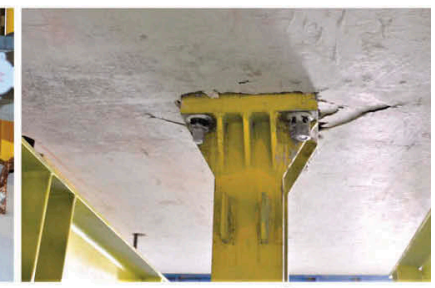

(f)

Figure 8. Pictures during the second phase of cyclic loading test: (a) Re-application of $V_{g}$; (b) $4.0 \%$ drift; (c) $5.5 \%$ drift; (d) Crack opening at $5.5 \%$ drift; (e) Punching failure (top surface); (f) Punching failure (bottom surface).

\subsubsection{Phase II}

No major developments were observed up to $3.0 \%$ drifts when the loading protocol was restarted from zero in the second phase. Cracking was already extensive at the end of Phase I. The re-application of the gravity load was done with no noticeable new cracks (Fig. 8a). Further opening of existing cracks was slow in the range of previously experienced drift ratios. At around $2.5 \%$ drift, the radial cracks opened considerably and reached the mid-thickness of the slab (this could be seen at the edge of the specimen).

Once the specimen reached the drift at which the test was stopped in the previous phase (i.e., 3.0\%), cracking started to develop at a higher rate. Cracking continued to develop all over the specimen (Fig. $8 \mathrm{~b}$ ). The bottom part of the slab around the column suffered severe concrete crushing starting from 3.5\% drifts. A crack along the direction perpendicular to the horizontal force became notably wide at drifts above $5.0 \%$ (Fig. $8 \mathrm{c}, \mathrm{d}$ ). The bottom part of the column punched through the slab of a few millimetres and continued to punch progressively with the increase of the drifts, until a one-sided punching failure occurred, outside the shear-reinforced zone (Fig. 8e,f). The largest drift successfully sustained by the specimen (i.e., before punching failure) was $5.5 \%$. The specimen was forced to reach the $6.0 \%$ drift level, but it failed at around $90 \mathrm{~mm}$ horizontal displacement.

\section{Analysis of Main Results}

The force-displacement (unbalanced moment-drift) relationship is shown in Fig. 9. The hysteresis loops of Phase I are distinguished by a grey fill in the figure. As expected, the initial stiffness of the specimen was not recovered at Phase II, in which the horizontal loading stiffness was considerably lower. As a result, the horizontal forces were also lower compared to Phase I for the same drifts. However, the horizontal force was gradually increased with the horizontal drift, until it reached values comparable to values attained in Phase I for $3.0-3.5 \%$ drift ratios. 


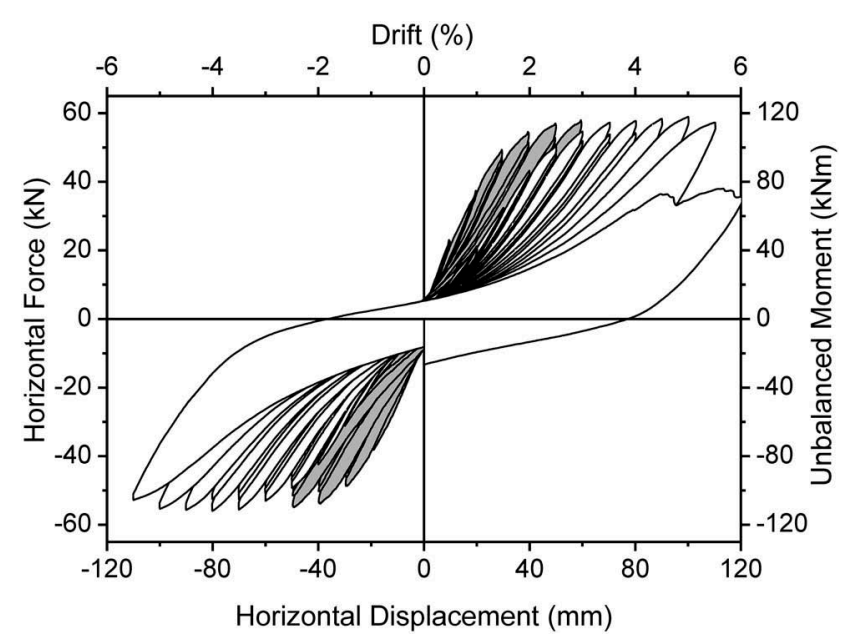

Figure 9. Force-displacement (unbalanced moment-drift) relationship (shaded area corresponds to Phase I).

The backbone curve constructed by joining the maximum horizontal forces at the first cycle in each drift ratio level of the loading protocol (Fig. 10) shows that there was a smooth transition between the two different loading phases. The specimen was able to sustain the gravity load for considerably high drifts while maintaining an almost constant horizontal force (unbalanced moment) at peak drifts. Figure 10 also shows a bilinear idealization of the response of the specimen. This bilinearization is determined on the basis of equal areas under the experimental and bilinear curve (equal energy), considering Phase I of loading.

A detailed analysis of the strain gauge readings can be found in Isufi, Pinho Ramos, and Lúcio (2019) where it is shown that by the end of loading Phase I, all instrumented bars along the transversal direction of the specimen had yielded, confirming the attainment of

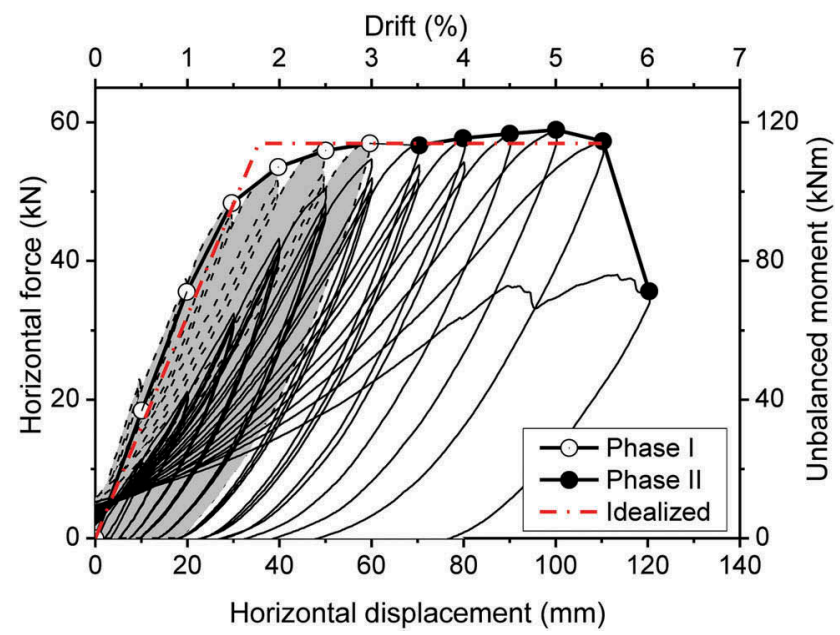

Figure 10. Backbone curve for positive displacements and the elastoplastic idealization. 
the maximum flexural capacity. Strain gauges installed in shear studs detected yielding in only a few studs close to the column transversally to the direction of loading. Yielding in these studs started at around $2.0 \%$ drifts.

In Fig. 11, the gravity load $V_{\mathrm{g}}$ is plotted as a function of the average increment of deflections at the borders of the specimen, $\Delta u$. The increment is measured as the difference between the actual value and the initial value at the beginning of the corresponding phase. Figure 12 shows the envelope curves for each cyclic loading phase. From Figs. 11 and 12 it is noticed that the vertical and the horizontal stiffness are both reduced in Phase II, due to the cracking already present from Phase I.

To compare the energy dissipation capacity of the specimen in Phases I and II and to observe the effect of repeated cyclic loading, an equivalent viscous damping coefficient $\xi_{\text {eq }}$ was calculated in Isufi, Pinho Ramos, and Lúcio (2019) for each complete cycle (i.e., excluding the

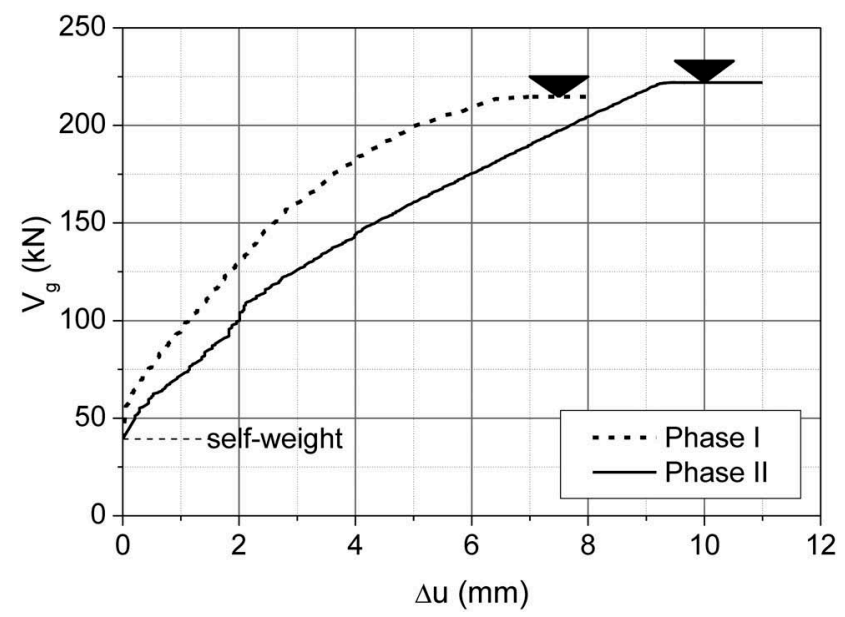

Figure 11. Gravity load-deflection relationship.

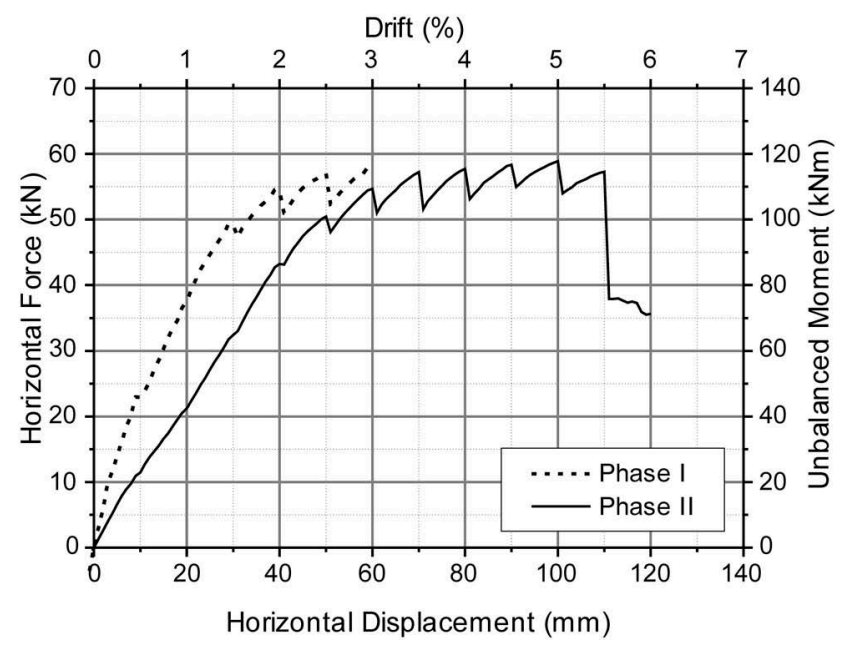

Figure 12. Envelope force-horizontal displacement relationship for horizontal loading. 
half-cycle at 3\% drift in Phase I and the last cycle in which punching failure occurred). The procedure outlined in Hose and Seible (1999) was followed, according to which the equivalent viscous damping coefficient can be calculated as:

$$
\xi_{e q}=\frac{1}{4 \pi}\left(\frac{E_{d 1}}{E_{S 1}}+\frac{E_{d 2}}{E_{S 2}}\right)
$$

where $E_{\mathrm{d} 1}$ and $E_{\mathrm{d} 2}$ are the areas within the hysteresis curve for positive and negative displacements, whereas $E_{\mathrm{S} 1}$ and $E_{\mathrm{S} 2}$ are the elastic strain energies for positive and negative displacements, respectively. The results are plotted in Fig. 13 for reference. In the figure, cycles of the same drift are distinguished by the size of the marker, with the largest marker representing the first excursion. The results show that cycle repetitions cause a decrease of the equivalent damping coefficient and the decrease is more pronounced in Phase I.

The Residual Deformation Index (RDI) is a parameter that is often used as an estimator of damage in structural elements subjected to earthquake loading. RDI is used here to compare the damage in the two phases and it is obtained as the ratio between the residual horizontal displacement $\Delta_{\mathrm{r}}$ and the ideal yield displacement $\Delta_{\mathrm{y}}$ (Hose and Seible 1999). Herein, the RDI is calculated for positive displacements only, and the ideal yield displacement $\Delta_{\mathrm{y}}$ is calculated from the backbone curve, idealized into an elastoplastic relationship (Fig. 10). RDI is calculated for each positive half-cycle and the results are plotted in Fig. 14. This figure shows that, for the drift ratios imposed in Phase I, the residual horizontal displacements are not substantially increased when the loading protocol is repeated (i.e., in Phase II). This fact can also be observed in Fig. 10. Also, the RDI values are not significantly influenced by the repetitions of drift excursions within the same loading phase. In the last cycle (at $6 \%$ drift), the RDI value is rapidly increased due to the increase in the residual horizontal displacement after punching failure. The evolution of RDI values presented in Fig. 14 correlates well with the visually assessed damage during the test.

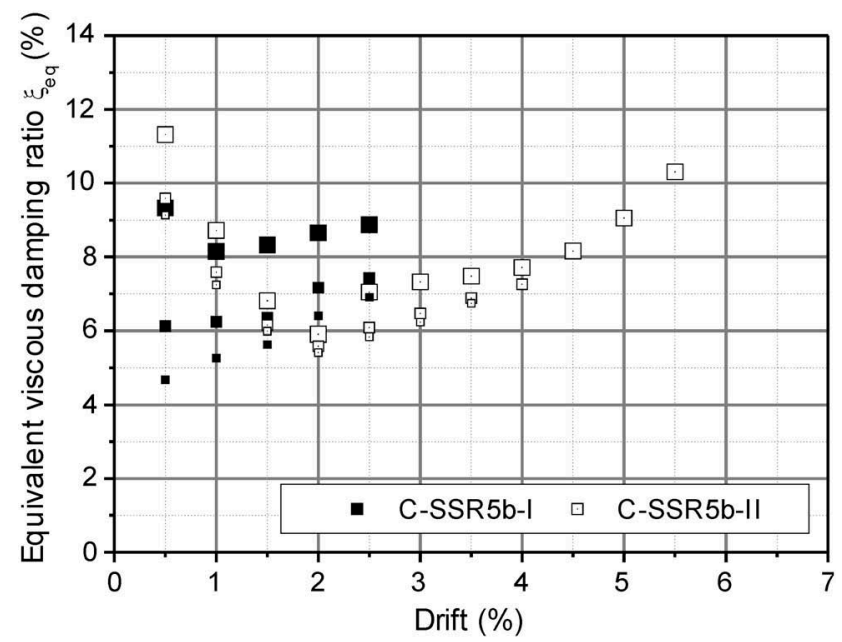

Figure 13. Equivalent viscous damping coefficients (Isufi, Pinho Ramos, and Lúcio 2019). 


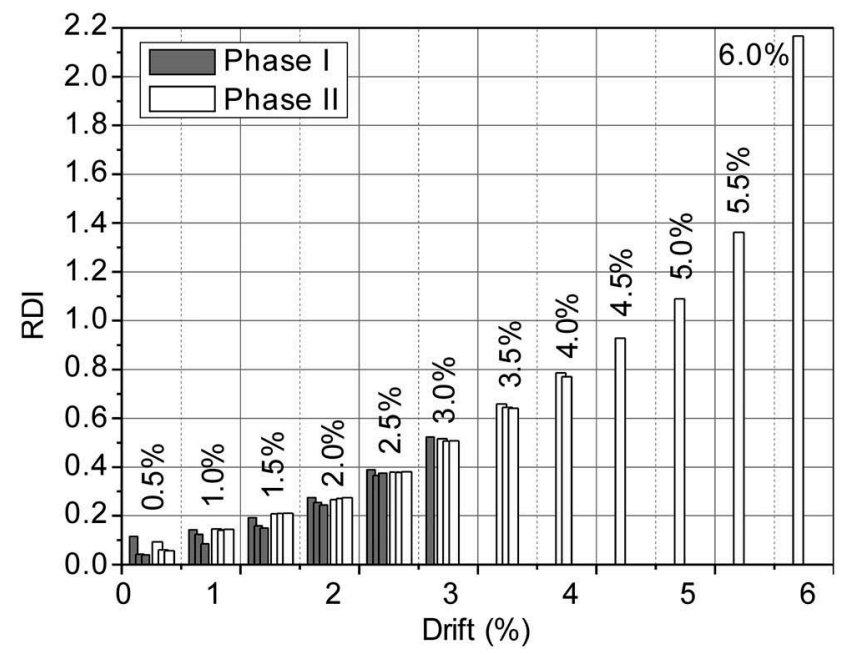

Figure 14. Residual Deformation Indices (RDI).

\section{Lateral Stiffness}

\subsection{Stiffness Degradation due to Repeated Loading}

The specimen is subjected to cycle repetitions within a loading phase and repetition of the same cycles in Phase II (Fig. 6). Stiffness degradation for both types of cycle repetitions is studied by looking at the secant (effective) stiffness, $K_{\mathrm{sc}}$, calculated based on Fig. 15a as the average of the secant stiffness for positive and negative half-cycle for each cycle. It should be noted, however, that the force-deformation response was reasonably symmetric (Fig. 9). For the calculation of stiffness, the elastic deformation of the column $\left(\delta_{\mathrm{e}, \mathrm{col}}\right)$ was taken out, as demonstrated in Fig. 15b.

The degradation of secant stiffness as a function of the dissipated energy is presented in Fig. 16. The dissipated energy is calculated as the area enclosed by the hysteresis curve up to zero displacement point marking the completion of the respective cycle. The figure demonstrates that there is a rapid stiffness degradation during the first horizontal cycles.
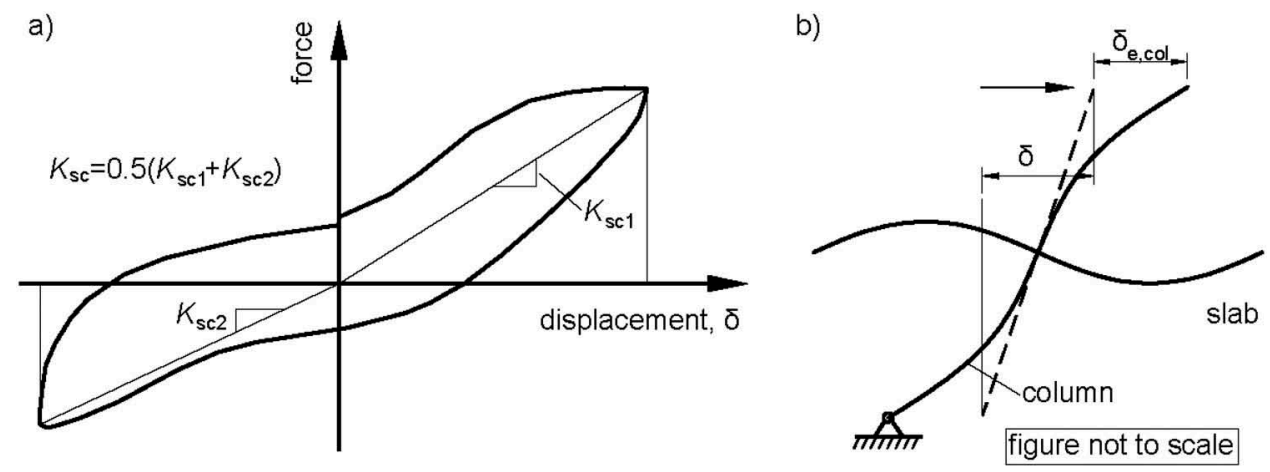

Figure 15. (a) Definition of secant stiffness from the force-displacement relationship and (b) the displacement used in stiffness calculation. 


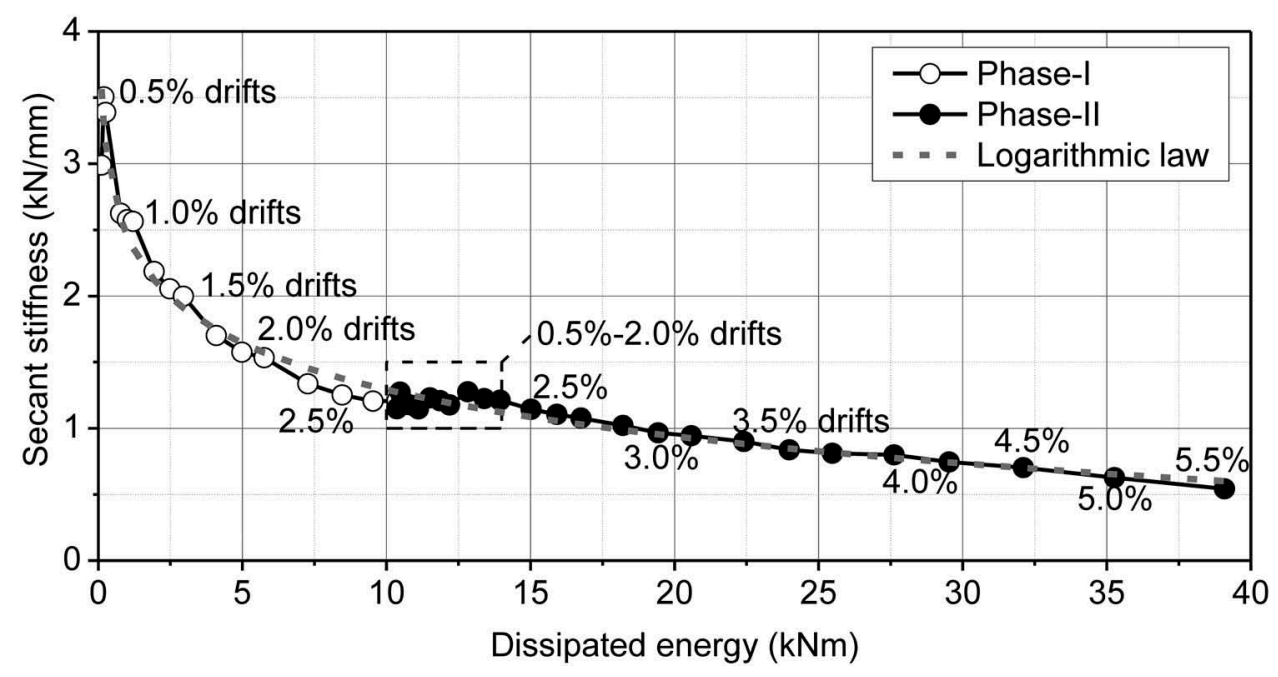

Figure 16. Secant stiffness as a function of dissipated energy.

Afterwards, the slope of the graph decreases, following reasonably well (with $R^{2}=0.97$ ) the logarithmic law below:

$$
K_{s c}=-0.507 \ln \left(E_{d}\right)+5.96
$$

where $E_{\mathrm{d}}$ is the dissipated energy in units " $\mathrm{kNmm}$ " and $K_{\mathrm{sc}}$ is expressed in " $\mathrm{kN} / \mathrm{mm}$ ".

The stiffness was continuously reduced throughout the test, both during cycle repetitions within the same phase and from Phase I to Phase II. However, the stiffness degradation was slower after the initial damage of the specimen. It is interesting to notice that there is a nearly horizontal plateau in the graph at the beginning of Phase II up to $2.0 \%$ drift ratios. In Fig. 10, this roughly corresponds to the initial branch of the bilinear curve. This means that, although the dissipated energy continued to increase when the cycles up to $2.0 \%$ drift were repeated in Phase II, there was almost no additional stiffness degradation until after relatively large horizontal drifts. The secant stiffness continued to decrease for severe horizontal loading, represented by earthquakes that impose drifts larger than $2.0 \%$ in the slab-column connections.

\subsection{Modelling for Elastic Linear Analysis}

In design practice for flat slabs, linear methods of analysis are preferred over nonlinear ones due to their simplicity and decreased computational effort and time. Finite element modelling and analysis have especially gained popularity with the development of computers and the gradual acceptance in design codes. However, the structural behaviour under horizontal actions is rarely linear elastic. Especially for earthquake loading, the structures are expected to behave nonlinearly. From Fig. 12, for example, it is noticed that the curve starts to deviate from the initial linear one for rather small horizontal displacements. The designer is therefore faced with the problem of choosing correct material and section properties to account for the nonlinear behaviour in a linear elastic analysis. 


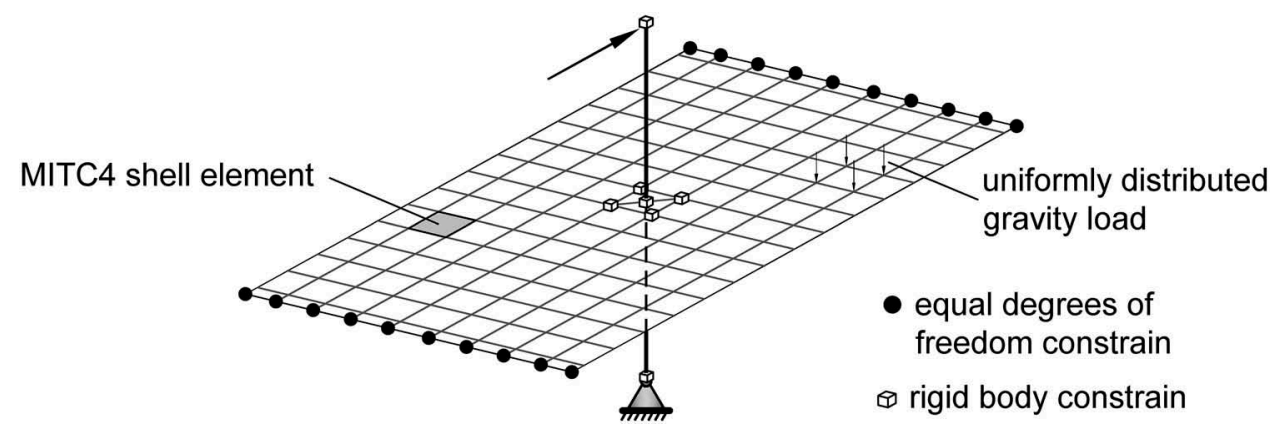

Figure 17. Model used to estimate the elastic stiffness.

To address this issue, a linear elastic model of the specimen was built in the OpenSees (McKenna, Scott, and Fenves (2010)) platform, as shown in Fig. 17. The column is modelled as rigid. The slab-column joint region $(250 \times 250 \times 150 \mathrm{~mm})$ is constrained to behave as a rigid body. Boundary conditions are set in accordance with the conditions enforced by the test setup (Figs. 2,5). This means that the finite element nodes in the midspan lines are constrained to have the same vertical deflection and rotation in the direction of loading and the column is pinned to the ground on the bottom end. The slab is modelled with overall dimensions $3.84 \times 1.85 \mathrm{~m}$ to account for the exact location of the subassemblies of the test setup (Figs. 2,5). Shell elements with 4 nodes, based on the theory of Mixed Interpolation of Tensorial Components (MITC4 element, Dvorkin and Bathe (1984)), were used. An elastic section was assigned to the shell elements, using the gross concrete section (depth $150 \mathrm{~mm}$ ) and modulus of elasticity in accordance with Table 1.

After the application of the gravity load, monotonically increasing horizontal displacements were applied. The results of the linear analysis are presented in Fig. 18 (curve "1.00E the enveloping curve of the specimen's response in both phases is also shown (considering a rigid column, taking out the elastic deformation of the steel column). As expected, the elastic model with gross cross section and uncracked material properties significantly overestimates

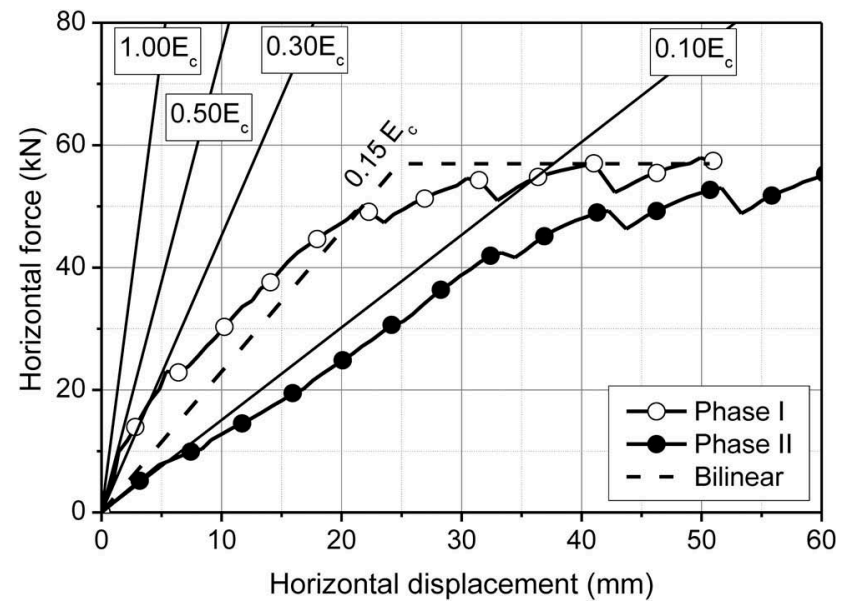

Figure 18. Comparison with elastic finite element models (rigid column). 
the stiffness of the specimen. The specimen was already cracked due to gravity loading at the beginning of the horizontal loading. As a result, the stiffness overestimation starts from the very beginning of horizontal loading (Fig. 18).

Results considering a reduction of the modulus of elasticity of concrete to $50 \%, 30 \%$, and $10 \%$ of the initial value are also plotted in Fig. 18 . The curve corresponding to $0.5 E_{\mathrm{c}}$ approximates reasonably well the initial stiffness of the specimen. However, the stiffness is rapidly decreased with the increase of horizontal displacements. The curve corresponding to $0.3 E_{\mathrm{c}}$ describes the initial stiffness more reasonably if the envelope curve is studied as a whole. The beginning of the second phase is described reasonably well by an elastic analysis in which the stiffness of the slab is reduced to $10 \%$ of the initial value. The stiffness of the approximated bilinear model is between the $0.1 E_{\mathrm{c}}$ and $0.3 E_{\mathrm{c}}$ curves. More precisely, the linear stiffness of the bilinear model is $15 \%$ of the elastic linear stiffness.

\subsection{Design Implications}

As already mentioned, Fig. 18 shows that the initial stiffness of the specimen is reduced due to cracking in the gravity loading phase. A comparison of the envelope curve of specimen C-SSR5b with other specimens tested in the same experimental campaign Isufi, Pinho Ramos, and Lúcio (2019), presented in Fig. 19, reveals that the initial stiffness is quite similar for all specimens, even though the gravity load varied by approximately 100 $\mathrm{kN}$ (GSR varied between 54\% for specimen C-SSR5b and 64\% for specimen C-SSR5c) and the modulus of elasticity of concrete varied by approximately $10 \mathrm{GPa}$ from specimen to specimen. All the specimens in Fig. 19 have shear reinforcement in the form of shear studs, except C-Ref which had no shear reinforcement. Specimen C-Ref had approximately the same GSR as specimen C-SSR5b but failed for a much lower drift (only 1.0\%) compared to all the shear-reinforced specimens, including C-SSR5b.

Using the model described in Fig. 17 to analyse the other specimens tested in a single phase in Isufi, Pinho Ramos, and Lúcio (2019), it was found that the initial stiffness of the

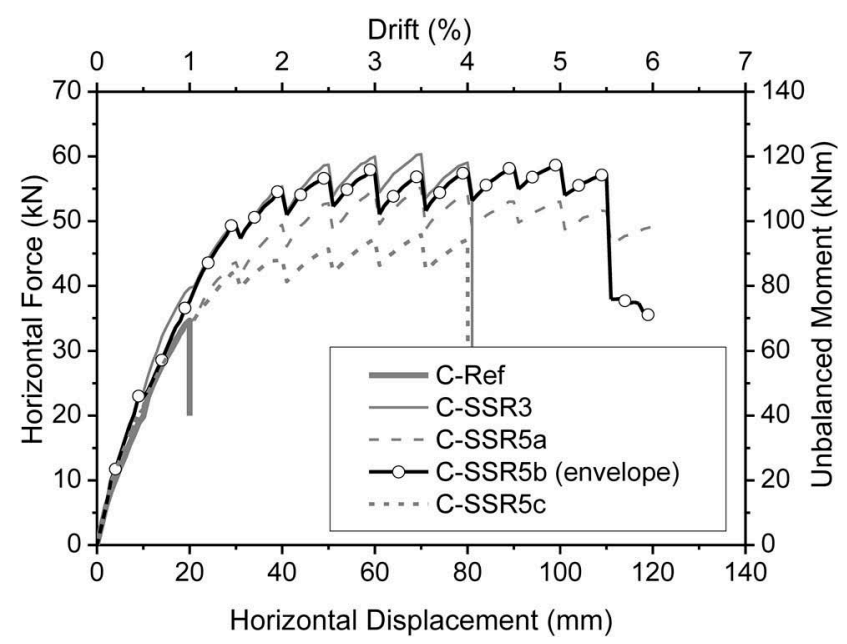

Figure 19. Comparison of envelope curves for specimens of Isufi, Pinho Ramos, and Lúcio (2019). 
bilinear approximation varies from $12 \%$ to $17 \%$ of the elastic stiffness. The largest reduction of the stiffness in relation to the elastic stiffness corresponds to specimen C-SSR5c, which had the highest gravity load (GSR of 64\%). This observation indicates that the magnitude of gravity loads influences the lateral stiffness, as previously acknowledged in Luo and Durrani (1995).

Design codes recommend a reduction of the stiffness of the elements to consider cracking. The presented analysis indicates that the reduction of the section properties can be as low as $15 \%$ of the uncracked properties for design purposes when conditions similar to those presented in this paper apply. An even lower value would be appropriate for higher gravity loads. The aforementioned value is considerably lower than that recommended in the codes. For example, Eurocode 8 (CEN 2004b) recommends a reduction to $50 \%$ (but with no specific reference to flat slabs) and ACI 318 ACI (2014) recommends a reduction from $25 \%$ to $50 \%$ of the uncracked stiffness for linear analysis (but refers the readers to the relevant literature for lateral loading). This means that the codes' basic recommendations are generally conservative in relation to the determination of forces (for example, the unbalanced moment with which the punching shear reinforcement is designed), but these code recommendations can lead to an underestimation of the displacements in seismic loading conditions if more detailed analyses are not performed.

A further reduction of the lateral stiffness to values below $10 \%$ of the uncracked properties can be reasonable for the analysis of flat slabs similar to C-SSR5b surviving a major earthquake. In this case, a more refined analysis can be performed by considering the dissipated energy during the earthquake, as demonstrated in Section 4.1. Further research on this topic, potentially involving a refined nonlinear finite element analysis (as conducted, for example, in Mamede, Pinho Ramos, and Faria (2013), Genikomsou and Polak (2015) and Torabian et al. (2019) for gravity loading conditions only and Setiawan, Vollum, and Macorini (2019) for cyclic loading) is recommended.

\section{Residual Deflections}

Using the terminology adopted in the Eurocodes, more precisely in Eurocode 8, Part 1 CEN 2004b, the flat slabs can be regarded as primary or secondary seismic elements. Eurocode 8 does not entirely cover flat slabs that are part of the lateral load resisting system, i.e. primary seismic elements, but aims to do so in the new generation of Eurocodes (Bisch 2018). Horizontal residual displacements, energy dissipation, and the stiffness of the slab-column connections against horizontal actions are especially important for such buildings. On the other hand, in buildings where earthquake resistance relies on shear walls, moment-resisting frames or braces, avoiding punching failures in slabcolumn connections, and limiting the repair works are more relevant aspects. Nonetheless, the deflections of the slab can be important in terms of serviceability, regardless of the slabs being primary or secondary seismic elements. Specimen C-SSR5b was already deflected at the beginning of Phase II, due to the applied gravity loads in Phase I and the degradation during cyclic loading under constant gravity loads.

As described in Fig. 20, the residual deflections at the borders of the specimen (i.e., at the mid-span of the prototype structure) for zero horizontal displacement kept increasing throughout the test, although the gravity load was kept constant. This observation is in contrast with the case of residual horizontal displacements, which remained almost 


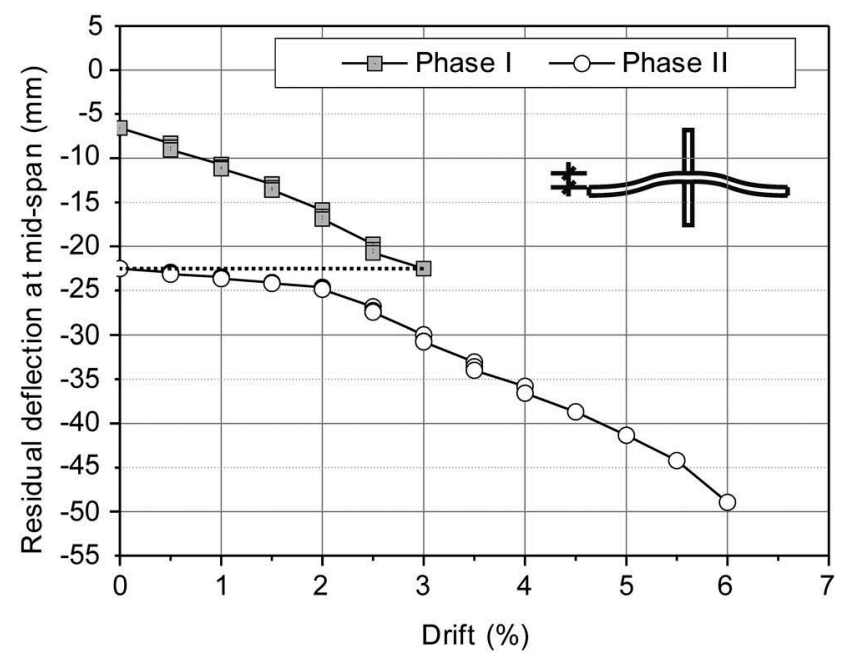

Figure 20. Evolution of residual deflections at the borders of the specimen for zero horizontal displacement at the end of different drift cycles.

unchanged from Phase I to Phase II (up to 3\% drift, refer to RDI in Section 3). Figure 20 also shows that the increase of deflections was lower in the second phase until $2 \%$ drifts, but then it continued to progress with a rate similar to that observed in Phase I. This roughly corresponds to the linear branch of the bilinear curve shown in Fig. 10. This continuous increase of deflections can lead to serviceability issues in a post-earthquake scenario for buildings containing flat slabs.

\section{Forces and Moments}

Throughout the test, the sagging (positive) bending moments at the borders of the specimen were monitored and adjusted to ensure equal rotations at the simulated midspans. The force was applied through a hydraulic actuator installed in the test setup struts (Fig. 5). Load cells monitored the compressive force in the struts and the total sagging moment at each border is calculated as the sum of forces in the strut multiplied by the corresponding lever arm. Before cyclic loading, the amount of force applied in test setup struts was determined based on a preliminary nonlinear analysis of the specimen. As a result, the sagging bending moments at the end of the gravity loading phase account for cracking of the specimen.

The evolution of sagging bending moments for specimen C-SSR5b for zero horizontal force is shown in Fig. 21. Within a cycle, the sagging moments fluctuated in relatively small amounts around the values presented in Fig. 21.

The figure reveals that the second phase was characterised by sagging moments that were only slightly larger compared to the first phase (around $5 \mathrm{kNm}$ ). It is noticed also that the graphs have two distinct parts: one from $0.0 \%$ to $2.0 \%$ drift and another from $2.0 \%$ drift to failure, which is characterized by a steeper slope. This distinct change of slope roughly corresponds to the rapid increase of residual deflections at mid-span, as can be seen from Fig. 20. 


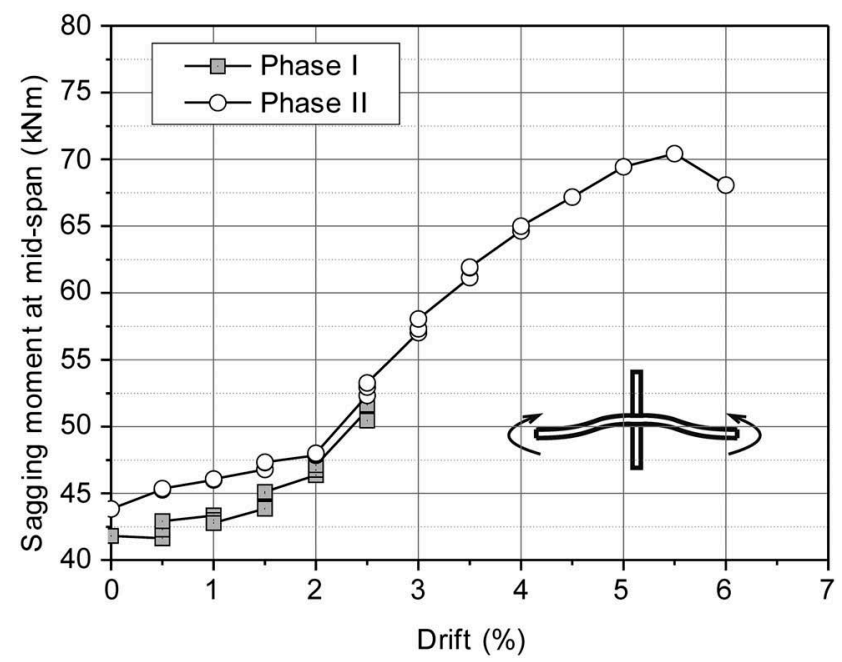

Figure 21. Evolution of sagging moments at zero horizontal force.

The sagging moments at the borders of the specimen are denoted by $M^{+}$in the free body diagram of Fig. 22. During the application of horizontal loads, $P$, the test setup reacts with the force $V_{\mathrm{TS}}$, which can be calculated by equilibrium. For simplicity, the self-weight of the slab and equipment is concentrated at the gravity load application points.

Figures 23 and 24 show the total bending moments at (a) the first excursion at each peak drift level, and (b) at zero horizontal force (i.e., corresponding to gravity loading only) along the test. The difference between these two bending moment diagrams produces the bending moment diagram (c) of the specimen under horizontal loads and zero gravity loads. These bending moment diagrams assume that the slab specimen acts as a "beam", as in the Effective Beam Width method of analysis (Hwang and Moehle 2000; Pecknold 1975). For the construction of the bending moment diagrams from gravity loads, the monitored positive bending moments at zero horizontal force were used.

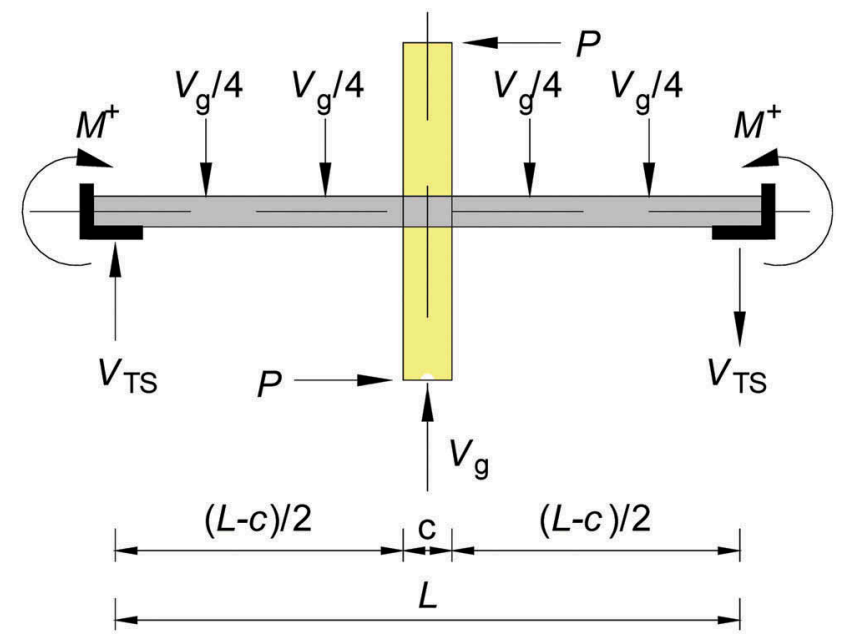

Figure 22. Free body diagram of the specimen under horizontal loads. 
a)

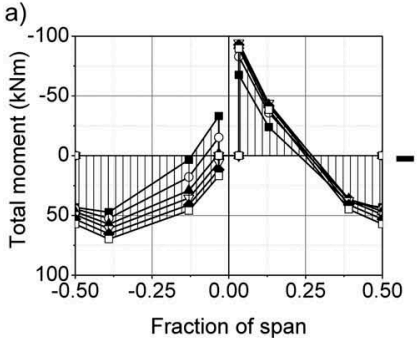

$-0.5 \%-0-1.0 \%$

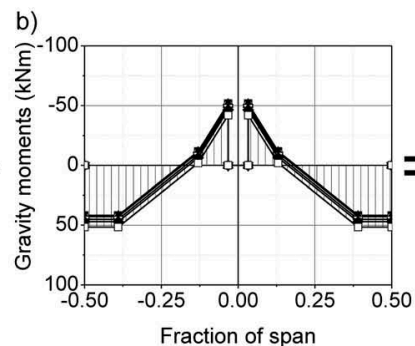

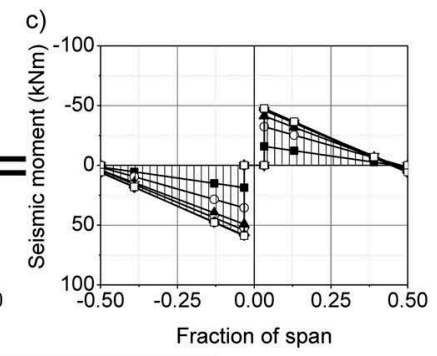

$-2.5 \%-\square-3.0 \%$

Figure 23. Total, gravity, and seismic bending moments in specimen C-SSR5b, Phase I.

a)

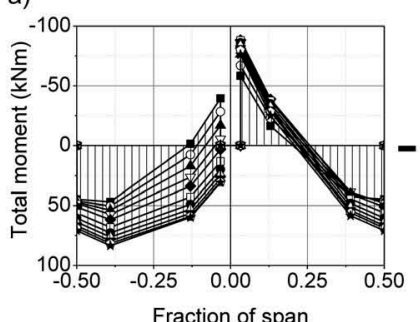

Fraction of span b)

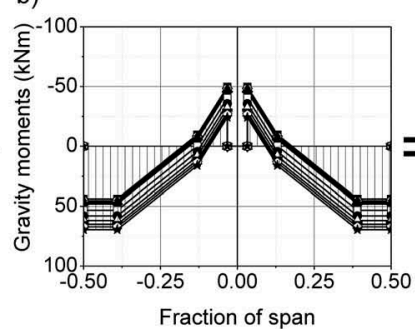

c)

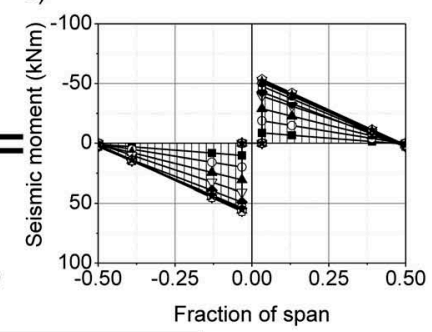

$-3.5 \% \multimap-1.0 \%$

$-1.5 \%-\nabla-2.0 \%$

$2.5 \%-\square-3.0 \%$

$5.5 \%$

Figure 24. Total, gravity, and seismic bending moments in specimen C-SSR5b, Phase II.

As expected, the shape of the seismically induced moment diagrams is triangular, with a value of zero near the simulated mid-span, at the borders of the specimen. Because of the symmetric nature of the bending moments due to gravity loading, the unbalanced moment calculated from the seismically induced moments is the same as the unbalanced moment calculated from the total bending moment diagram or from the measured horizontal force.

As demonstrated in previous publications using the same test setup (Almeida et al. 2016; Gouveia, Faria, and Ramos 2019; Isufi, Pinho Ramos, and Lúcio 2019), the test setup allows bending moment redistribution during the test. As damage progresses, the sagging (positive) bending moments are continually increased while the hogging (negative) bending moments are increased until yielding of the top reinforcement, forcing after that a moment redistribution towards the span. The slab did not reach its flexural failure limit, because it did not reach its plastic sagging moment resistance at midspan.

It is noticed that sagging total bending moments are present at the face of the column, i.e.,, bending moment sign reversal occurred at both phases (Figs. 23 and 24). However, sign reversal was postponed in the second phase, due to the already redistributed hogging moments from the first phase.

\section{Comparison of Drift Capacity with Similar Specimens}

Flat slabs without shear reinforcement have a very limited displacement capacity (Hueste et al. 2007; Pan and Moehle 1989). A similar specimen tested under the same conditions, 
with similar longitudinal reinforcement and comparable material characteristics and gravity loading but without shear reinforcement was presented in Almeida et al. (2016), named C-50. Specimen C-50 was similar to specimen C-Ref (without shear reinforcement) described in Isufi, Pinho Ramos, and Lúcio (2019). Both specimens without shear reinforcement (C-50 and C-Ref) failed in a brittle punching shear failure mode, at around $1.0 \%$ drift ratio. Two other specimens without shear reinforcement, C-40 and C-30 Almeida et al. (2016), although having considerably lower gravity loads (GSR of 40\% and $30 \%$, respectively), failed in punching for drifts $1.5 \%$ and $2.0 \%$, respectively. These drift ratios are considerably lower than the drift experienced by C-SSR5b with shear studs, even though it was tested under a two-phase loading protocol.

Comparing the ultimate drift of C-SSR5b with other specimens with the same flexural and shear reinforcement layout that were tested in a single phase in the same experimental campaign Isufi, Pinho Ramos, and Lúcio (2019), it is shown that the ultimate drift capacity of the specimen was not significantly impaired by the two-phase loading protocol. Referring to Fig. 19, it is noticed that the ultimate drift ratio equal to $5.5 \%$ of the specimen C-SSR5b is between the ultimate drifts of specimen C-SSR5c which had an increased GSR and specimen C-SSR5a, which had approximately the same GSR but a lower gravity load because of the lower concrete compressive strength.

\section{Conclusions}

The reversed horizontal cyclic loading test of a flat-slab specimen reinforced with headed shear studs was presented. A two-phase loading protocol was followed to study the postearthquake performance of the flat slab-column assembly. Although the specimen was loaded up to considerably high drift ratios in the first phase $(3.0 \%$ drift), it was able to sustain further deformations in the second phase, while successfully carrying the imposed gravity loads until failure.

The ultimate drift capacity of the specimen was relatively high (5.5\%), and comparable with that of specimens with similar characteristics but tested under reversed horizontal cyclic loading in a single phase (i.e., specimens C-SSR5a and C-SS5c in Isufi, Pinho Ramos, and Lúcio (2019)). The drift capacity was not significantly impaired by the twophase loading protocol, which is a desirable behaviour in seismic loading conditions.

The second phase was characterized by a reduced loading stiffness and lower horizontal forces for the same drift, which can be regarded as a negative aspect of the postearthquake behaviour for the special case of flat slabs designated as primary seismic elements. In this case, both the deformation capacity and the stiffness are important in resisting future earthquakes. A reduction of the lateral stiffness of primary slab-column connections can result in a lengthening of the fundamental period of vibrations of the structure, potentially leading to an increased displacement demand. It was shown, however, that significant further stiffness degradation occurred only for strong returning earthquakes, and almost no additional degradation occurred for repeated drifts smaller than the yielding drift. In the most common case of flat slabs being secondary seismic elements, the reduction of stiffness after the first earthquake is of minor importance as long as the drift capacity is not impaired.

It was shown that the cracked lateral stiffness of flat slab-column connections to be used for linear analysis can be lower than the current code recommendations. The 
magnitude of gravity loads influences the reduction of lateral stiffness. The overestimation of stiffness for linear analysis in codes generally leads to a safe design in terms of forces (and stresses) in the flat slab. However, when the contribution of flat slabs in the lateral load resisting system is taken into account (for example, when there are no shear walls, or when the flat slabs are taken into account to realistically model structures susceptible to torsional vibrations due to the irregular distribution of mass), the overestimation of lateral stiffness can lead to an underestimation of horizontal displacements.

Repeated horizontal loading caused continuous degradation of the bending stiffness of the slab, resulting in a continuous increase of deflections throughout the entire test. Such deflections can become critical for the serviceability of the structure after seismic loading, regardless of the designation of the flat slabs as primary or secondary seismic elements.

Further research, including nonlinear analyses and experimental research focused on thicker flat slabs and varying values of GSR and the flexural reinforcement ratio, is recommended for a more complete post-earthquake performance assessment framework of slab-column connections.

\section{ORCID}

Brisid Isufi (10 http://orcid.org/0000-0002-6495-8715

António Pinho Ramos (D) http://orcid.org/0000-0001-9496-4991

Válter Lúcio (D) http://orcid.org/0000-0002-5864-551X

\section{References}

ACI. 2014. Building code requirements for structural concrete (ACI 318-14) and commentary on building code requirements for structural concrete (ACI 318R-14). Farmington Hills, MI, USA: American Concrete Institute.

Almeida, A. F., M. M. Inácio, V. J. Lúcio, and A. P. Ramos. 2016. Punching behaviour of RC flat slabs under reversed horizontal cyclic loading. Engineering Structures 117: 204-19. doi: 10.1016/j. engstruct.2016.03.007.

Bisch, P. 2018. Eurocode 8. evolution or revolution? In Recent advances in earthquake engineering in Europe. ECEE 2018. Geotechnical, geological and earthquake engineering, ed. K. Pitilakis, 639-60. Cham, Switzerland: Springer International Publishing.

CEN. 2004a. EN 1992-1-1.Eurocode 2: Design of concrete structures - part 1-1: General rules and rules for buildings. Brussels, Belgium: CEN.

CEN. 2004b. EN 1998-1, Eurocode 8: Design of structures for earthquake resistance - part 1: General rules, seismic actions and rules for buildings. Brussels, Belgium: CEN.

Dvorkin, E. N., and K.-J. Bathe. 1984. A continuum mechanics based four-node shell element for general non-linear analysis. Engineering Computations 1 (1): 77-88. doi: 10.1108/eb023562.

Farhey, D. N., M. A. Adin, and D. Z. Yankelevsky. 1995. Repaired RC flat-slab-column subassemblages under lateral loading. ASCE Journal of Structural Engineering 121 (11): 1710-20. doi: 10.1061/(ASCE)0733-9445(1995)121:11(1710).

Faria, D. M., V. J. Lúcio, and A. P. Ramos. 2012. Post-punching behaviour of flat slabs strengthened with a new technique using post-tensioning. Engineering Structures 40: 383-97. doi: 10.1016/j. engstruct.2012.03.014.

Genikomsou, A. S., and M. A. Polak. 2015. Finite element analysis of punching shear of concrete slabs using damaged plasticity model in ABAQUS. Engineering Structures 98: 38-48. doi: 10.1016/j.engstruct.2015.04.016. 
Gouveia, N. D., D. M. Faria, and A. P. Ramos. 2019. Assessment of SFRC flat slab punching behaviour-part II: Reversed horizontal cyclic loading. Magazine of Concrete Research 71 (1): $1-70$.

Habibi, F., W. D. Cook, and D. Mitchell. 2014. Predicting post-punching shear response of slab-column connections. ACI Structural Journal 111 (1): 123-34.

Hose, Y. D., and F. Seible. 1999. Performance evaluation database for concrete bridge components and systems under simulated seismic loads. PEER 1999/11. Berkeley, California, USA: Pacific Earthquake Engineering Research Center, College of Engineering, University of California.

Hueste, M. D., J. Browning, A. Lepage, and J. W. Wallace. 2007. Seismic design criteria for slab-column connections. ACI Structural Journal 104 (4): 448-58.

Hwang, S.-J., and J. Moehle. 2000. Models for laterally loaded slab-column frames. ACI Structural Journal 97 (2): 345-52.

Isufi, B., A. Pinho Ramos, and V. Lúcio. 2019. Reversed horizontal cyclic loading tests of flat slab specimens with studs as shear reinforcement. Structural Concrete 20 (1): 330-47. doi: 10.1002/ suco.2019.20.issue-1.

Koppitz, R., A. Kenel, and T. Keller. 2015. Effect of load history on punching shear resistance of flat slabs. Engineering Structures 90: 130-42. doi: 10.1016/j.engstruct.2015.02.016.

Luo, Y. H., and A. J. Durrani. 1995. Equivalent beam model for flat-slab buildings-part 1: Interior connections. ACI Structural Journal 92 (1): 115-24.

Mamede, N. F. S., A. Pinho Ramos, and D. M. V. Faria. 2013. Experimental and parametric 3D nonlinear finite element analysis on punching of flat slabs with orthogonal reinforcement. Engineering Structures 48: 442-57. doi: 10.1016/j.engstruct.2012.09.035.

Marder, K. J., C. J. Motter, K. J. Elwood, and G. C. Clifton. 2018. Effects of variation in loading protocol on the strength and deformation capacity of ductile reinforced concrete beams. Earthquake Engineering \& Structural Dynamics 47: 2195-213. doi: 10.1002/eqe.3064.

Marquis, F., J. J. Kim, K. J. Elwood, and S. E. Chang. 2017. Understanding post-earthquake decisions on multi-storey concrete buildings in Christchurch, New Zealand. Bulletin of Earthquake Engineering 15 (2): 731-58. doi: 10.1007/s10518-015-9772-8.

McKenna, F., M. H. Scott, and G. L. Fenves. 2010. Nonlinear finite element analysis software architecture using object composition. Journal of Computing in Civil Engineering 24 (1): 95-107. doi: 10.1061/(ASCE)CP.1943-5487.0000002.

Megally, S., and A. Ghali. 2000. Seismic behavior of slab-column connections. Canadian Journal of Civil Engineering 27 (1): 84-100. doi: 10.1139/199-052.

Melo, G., and P. E. Regan. 1998. Post-punching resistance of connections between flat slabs and interior columns. Magazine of Concrete Research 50 (4): 319-27. doi: 10.1680/macr.1998.50.4.319.

Mitchell, D., and W. D. Cook. 1984. Preventing progressive collapse of slab structures. Journal of Structural Engineering 110 (7): 1513-32. doi: 10.1061/(ASCE)0733-9445(1984)110:7(1513).

Pan, A., and J. P. Moehle. 1989. Lateral displacement ductility of reinforced concrete flat plates. ACI Structural Journal 86 (3): 250-58.

Pan, A. D., and J. P. Moehle. 1992. An experimental study of slab-column connections. ACI Structural Journal 89 (6): 626-38.

Pecknold, D. 1975. Slab effective width for equivalent frame analysis. ACI Journal Proceedings 72 (4): 135-37.

Ramos, A. P., and V. Lúcio. 2008. Post-punching behaviour of prestressed concrete. Magazine of Concrete Research 60 (4): 245-51. doi: 10.1680/macr.2008.60.4.245.

Robertson, I. N., and G. Johnson. 2004. Repair of slab-column connections using epoxy and carbon fiber reinforced polymer. ASCE Journal of Composites for Construction 8 (5): 376-83. doi: 10.1061/(ASCE)1090-0268(2004)8:5(376).

Ruiz, M. F., Y. Mirzaei, and A. Muttoni. 2013. Post-punching behavior of flat slabs. ACI Structural Journal 110 (5): 801-12.

Setiawan, A., R. Vollum, and L. Macorini. 2019. Numerical and analytical investigation of internal slab-column connections subject to cyclic loading. Engineering Structures 184: 535-54. doi: 10.1016/j.engstruct.2019.01.089. 
Torabian, A., B. Isufi, D. Mostofinejad, and A. P. Ramos. 2019. Behavior of thin lightly reinforced flat slabs under concentric loading. Engineering Structures 196: 109327. doi: 10.1016/j. engstruct.2019.109327.

Widianto, O. Bayrak, J. O. Jirsa, and Y. Tian. 2010. Seismic rehabilitation of slab-column connections. ACI Structural Journal 107 (2): 237-47. 